\title{
Visual acuity in children as a function of hue
}

\author{
EUGENE SKOFF ${ }^{2,3}$ AND ROBERT H. POLLACK ${ }^{4}$ \\ INSTITUTE FOR JUVENILE RESEARCH, CHICAGO
}

Ninety-six suburban school children, 7 to 14 years old, were tested, with colored parallel bars as acuity targets, to assess relative effects of hue, age, and intelligence on visual acuity. The main effects of color and age were found to be significant but with no significant interaction. A one-way analysis of variance for each color indicated blue and black acuity improved with age while red did not. Since natural myopia for blue light may have accounted for the effect with blue, a second experiment was undertaken with focusing being introduced as a variable. Focusing eliminated the effect of age, but the color effect remained significant. Lowest resolution thresholds were obtained with black, next red, and blue highest. There was no relationship between acuity and intelligence nor were there any sex differences.

Studies concerning visual acuity have in the main a common focus on variables of light intensity and figure-ground contrast. With the exception of MacAdam (1949), Cavonius and Schumacher (1965), and more recently Bishop (1966a, b), few workers have studied the influence of color contrast alone on visual acuity. The present authors, in a pilot experiment on which the present study was based, found that foveal acuity based on hue contrast alone was significantly higher for red than for blue in two adult Ss. In view of the above work, one of the purposes of the present study was to further delineate the role of color contrast in visual acuity.

A second purpose of the present research was to provide quantitative data on the ontogenetic course of both chromatic and achromatic visual acuity. Based on research by Brody (1955) and Weale (1961a, b), Pollack (1963) demonstrated that contour detectability as a function of light intensity decreases with age; however, hue detection thresholds (Pollack, 1965a) did not follow anticipated ontogenetic trends. Pollack, therefore, concluded that contour detection and hue detection processes are underlain by different receptor systems with different ontogenetic trends. On the basis of the contour detectability work, it was hypothesized that fine acuity involving minimal separations of small black stimuli on a white ground, should be better in young children than in older children. On the other hand, it was hypothesized that fine acuity involving stimuli that differed from ground only in hue, and not in brightness, should show no age trend.

\section{Subjects}

\section{EXPERIMENT 1}

Ss were 96 elementary and junior high school students 5 residing in a white, middle-to-upper-class suburban area. Ages ranged from 7 to 14 years; Lorge-Thorndike IQs ranged from 91 to 139 with a mean IQ of 113 . There were 12 Ss in each of the eight age groups, six boys and six girls matched for age. Each $S$ had 20/20 uncorrected vision with no color defects as determined by testing with a Bausch and Lomb Master Orthorater and the American Optical Company's Pseudoisochromatic Plates. Experimentation was conducted in a mobile research laboratory.

\section{Apparatus}

The apparatus was a custom-designed Distance Simulator. ${ }^{6}$ The instrument was enclosed in a box of Masonite construction whose length was $773 / 4$ in., width 15 in., and depth 16 in. The entire box was painted a nonglare black. A felt viewing hood at one end of the box covered a binocular lens system with an adjustment for individual interpupillary distance. The lens system simulated a viewing distance of $67.5 \mathrm{ft}$ at an actual distance of $176.1 \mathrm{~cm}$. The far end of the box contained a modified commercial slide projector (Sawyer) with only the slide-changing mechanism retained, allowing the stimuli to be changed by a remote control unit. The stimuli were front-lit by Illuminant $C$ and illumination level was held constant by a Raytheon ACR-500 voltage regulator. Interposed between the light source and the stimulus was an electronically operated shutter that permitted a stimulus exposure ranging from $1 / 10$ to $100 \mathrm{sec}$. A pushbutton control activated the shutter.

The stimuli consisted of two parallel bars. The width of each bar subtended a visual angle of $1 \mathrm{~min}$ and the length subtended $4 \mathrm{~min}$. The background of the bars extended the full limit of a 2 in. $x 2$ in. slide subtending a visual angle of $8.3 \mathrm{~min} \times 8.3 \mathrm{~min}$. Separations between the colored bars varied from $5 \mathrm{sec}$ to $60 \mathrm{sec}$ in steps of $5 \mathrm{sec}$ of arc. Separations between black bars ranged from $2.5 \mathrm{sec}$ to $40.0 \mathrm{sec}$ with $2.5 \mathrm{sec}$ of arc between each step. After much experimentation with different saturation values to obtain optimal figure-ground contrast for visibility and in consideration of brightness matches available, the Munsell values

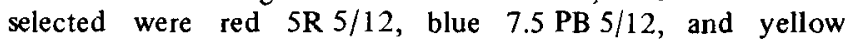
$5 Y 8 / 12$. Unfortunately, a saturation match with green was not available. The neutral gray background for the red and blue hues was $\mathrm{N} / 5$ and for the yellow, N/8. A .3 Wratten neutral-density filter was used with yellow to provide a brightness match with the other two hues. The selection of this filter, from the neutral density series, was based on visual matching by two independent judges. The Munsell value for the black bars was $\mathrm{N} 1.5 /$ mounted on a background of $\mathrm{N} 9.5 /$.

\section{Procedure}

After a $5-\mathrm{min}$ period of dark adaptation and with the head in the viewing position, $S$ was shown a slide with maximum separation and one with minimum separation. He was instructed to respond "Yes" when a gap between the bars was seen and "No" when a gap was not visible. Prior to actual testing $S$ was given a practice series of slides to ensure that instructions were understood. Catch stimuli consisting of a solid bar equal to the width of two bars were inserted into each series of slides to make sure that $S$ was responding properly to the visual display. The method of limits was used with eight trials presented in counterbalanced order for each hue. Prior experimentation indicated that a l-sec sijde exposure was optimal for clear bar discrimination. As children frequently reported eye fatigue, rest periods were liberally given. Each $S$ experienced all five acuity conditions with a 1- to 2-day interval between each condition.

\section{Results}

Since no thresholds could be obtained with the yellow stimuli, only the results with the red, blue, and black bars can be reported here. In general, Ss reported that separations between the yellow bars could not be seen because they were "too blurry," indicating that their contours were unstable. This blurredness of yellow is consistent with the findings of Teft and Wiener's $(1965)^{7}$ study 


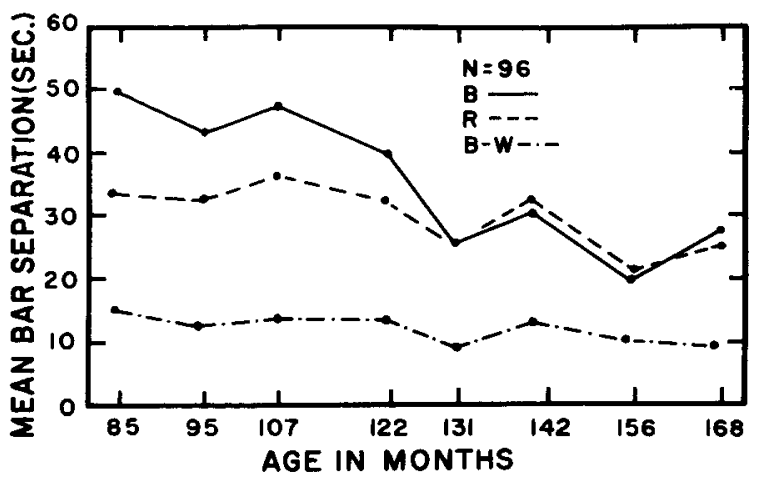

Fig. 1. Experiment 1-Visual acuity as a function of hue and chronological age.

on the effect of hue on masking of letters in which yellow letters were masked significantly more often than red, green, or blue letters.

Mean thresholds were calculated for each $S$ on the basis of eight trials per hue. The results of Experiment 1 are graphically portrayed in Fig. 1, where it can be seen that the lowest acuity thresholds were obtained with black-white, followed by red, with blue highest.

Wilson's (1956) distribution-free analysis of variance for age by color yielded a total $\chi^{2}$ of $154.73, \mathrm{df}=23, \mathrm{p}<.01$. The analy sis yielded a main effect of age $\left(\chi^{2}=14.78, \mathrm{df}=7, \mathrm{p}<.05\right)$ and color $\left(\chi^{2}=130.37, \quad \mathrm{df}=2, \quad \mathrm{p}<.01\right)$, but no significant interaction between age and color $\left(\chi^{2}=5.44, \mathrm{df}=14\right)$. Mann Whitney U tests, used to compare pairs of colors, were significant beyond the .001 level of confidence except red vs blue, where significance was at the .05 confidence level. A Kruskal-Wallis one-way analysis of variance by ranks for each color yielded a significant age trend for blue $\left(\chi^{2}=34.07, \mathrm{df}=7, \mathrm{p}<.001\right)$ and black-white $\left(\chi^{2}=18.32, \mathrm{df}=7, \mathrm{p}<.02\right)$, but not for red $\left(\chi^{2}=13.06, \mathrm{df}=7\right)$.

A separate analysis, conducted to determine the presence of sex differences, was not significant $(F=.62, \mathrm{df}=1)$.

\section{EXPERIMENT 2}

On the basis of work reported by Baker (1949) and Eckardt (1966) that indicated a natural myopia for blue objects with foveal vision, Experiment 2 was undertaken to determine what influence this variable may have had on the results of Experiment 1. Experiment 2 was a replication of Experiment 1, using the same $S s$, with only the instructions to $S$ and the procedure slightly modified.

Before the experimental series for each color actually began, $S$ was shown two focusing slides-one slide with the bars at a maximum perceptible separation and the other with bars at a minimum separation. With a pencil, E traced the contours of the bars for $S$ and instructed him that when he again saw the slides in the simulator, he was to concentrate on the edges of the bars so that they would appear sharp and clear. After dark adaptation, the slides were shown to $S$ in the simulator. Four focusing trials were given with each slide, each slide being exposed for $4 \mathrm{sec}$ followed by a recovery period of $4 \mathrm{sec}$ before the next trial. Thus, eight focusing trials were given: four with the bars at a minimum separation and four with the bars at a maximum separation. The experimental series began immediately after the focusing trials. It was hoped that the above procedure would minimize the influence of myopia for blue objects.

\section{Results}

Wilson's distribution-free analysis of variance was computed
Table 1

Summary of Analysis of Variance Scores for Experiment $I$ and Experiment II

\begin{tabular}{lrcccr}
\hline & \multicolumn{2}{c}{ Experiment I } & \multicolumn{2}{c}{ Experiment II } & \\
& \multicolumn{1}{c}{$\mathrm{X}^{2}$} & $\mathrm{P}$ & $\mathrm{X}^{2}$ & $\mathrm{P}$ & df \\
\hline Total & 154.73 & $<.01$ & 127.60 & $<.01$ & 23 \\
Age & 14.78 & $<.05$ & 2.96 & n.s. & 7 \\
Color & 130.37 & $<.01$ & 119.20 & $<.01$ & 2 \\
Age X Color & 5.44 & n.s. & 9.58 & n.s. & 14 \\
\hline
\end{tabular}

Note-Full tables sent on request.

for a color by replication (Experiment 1, Experiment 2) by age schema. The analysis yielded a total $\chi^{2}$ of $296.70, \mathrm{df}=47$, $\mathrm{p}<.01$. The main effects of color $\left(\chi^{2}=232.05, \mathrm{df}=2, \mathrm{p}<.01\right)$ and replication $\left(\chi^{2}=18.06, \mathrm{df}=1, \mathrm{p}<.01\right)$ were significant, while the effect of age $\left(\chi^{2}=11.58, \mathrm{df}=7\right)$ was not. The only significant interaction was that between color and replication $\left(\chi^{2}=12.6, \mathrm{df}=2, \mathrm{p}<.01\right)$. The Mann Whitney $\mathrm{U}$ tests between all colors were significant beyond the .001 level. For purposes of comparison, the results of the separate analyses for both experiments are summarized in Table 1 . As can be seen, only the color effect remained significant after focusing.

An analysis of sex differences and acuity was not made since it was felt that the introduction of focusing instructions in Experiment 2 would not appreciably alter the nonsignificant result obtained in Experiment 1.

Rank order (rho) correlations were computed between each acuity condition-red (R), blue (B), black-white (BW), and IQ (Lorge-Thorndike) for each age group separately. None of the correlations was significant.

\section{DISCUSSION}

In terms of chromatic acuity, when target and ground were of equal brightness, differences in visual acuity based on hue contrast alone were obtained. This result supports similar findings by MacAdam (1949), Cavonius and Schumacher (1965), and Bishop (1966a). Although focusing eliminated the age trend for blue obtained in Experiment 1, hue differences remained.

In addition to eliminating the age trend for blue, focusing produced other observable differences in Experiment 2 (Fig. 2).

As can be seen, resolution thresholds for red and blue were generally lower than in Experiment 1. Focusing practice appears to have improved acuity most conspicuously at the early age levels. Comparative improvement of blue was about $25 \%$ over that of red at 7 years old but with a decreasing percentage of improvement to 11 years old. At 12 years old, the percentage of improvement progressively increased in favor of red to the 14-year-old group where improvement was about $80 \%$ greater than that of blue. Thresholds for black-white were only very slightly lower after focusing.

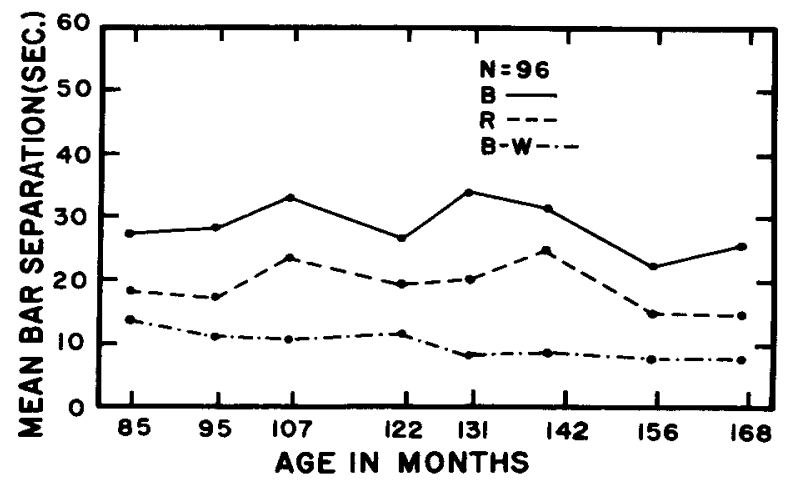

Fig. 2. Experiment 2-Visual acuity as a function of hue and chronological age with pretrial focusing. 
Since contour detection ability based on brightness contrast decreases with age (Pollack, 1963), it would be expected that acuity would also decrease with age. In the present study, there was no discernible age trend. However, brightness was held constant for all of the conditions in the present study, whereas it was systematically varied in the contour study. Further, brightness contrast with the black bars was distinctly suprathreshold; if the brightness of the background were to be systematically varied and threshold conditions were approached, a more appropriate comparison with the contour study could be made. Finally, the task in the contour study was simply the detection of the presence of an edge, where, on the other hand, the task in the present study involved the actual resolution of two contours. The $1 \cdot \mathrm{sec}$ exposure of parallel contours may have provided time for the attraction of contours, the amount of which decreases with age (Pollack, 1965b). The separations may "close up" more for the younger children than for the older. It seems possible that older children are generally reported to have better acuity than younger children due to the nature of the tasks, which generally involve the detection of a separation between parallel contours. Thus, the poorer acuity scores for younger children may be due, not to their inability to see fine details, but to their greater susceptibility to the attraction of parallel contours.

Although focusing eliminated the age trend for blue, no changes in relative superiority of colors took place in Experiment 2, i.e., blue thresholds still remained highest, red next, and black lowest. This is in contrast to Baker's (1949) study on vernier acuity where acuity for red was best and for blue least. However, after refractive correction was made for blue light, color superiority was reversed-blue acuity was better than red acuity. Since Baker used two Ss to demonstrate red superiority over blue, and then used only one $S$ in the refractive correction condition, her results may have been confounded by the wide individual differences in depth of macular pigmentation. Wald (1945) relates that one of his Ss had a virtually unpigmented macula, while in another $\mathrm{S}$ the pigment absorbed more than $90 \%$ of the blue light. Wald points out that these wide pigment differences may well account for disparate results in vision research reported in the literature. The fewer the Ss in a study, the more likely is the confounding effect of macular pigmentation differences.

The absence of age trends in chromatic acuity is in accord with Pollack's (1965a) findings where no age trends in hue detectability thresholds were obtained, and also where orange was easier to detect than either blue or green. In that same study, no correlation was found between hue detection and IQ, which is in agreement with the present study where no correlation was found between acuity and IQ. Dispensa (1939) and Slaton and Jorgenson (1958) likewise found no correlation between intellectual ability and visual acuity. In contrast, Loranger and Misiak (1959) report that acuity can be related to intelligence, and Pollack (1963) reports a correlation $(r=-.33, p<.05)$ between contour detectability thresholds and IQ. Weale (1963) points out that relationships between intelligence or age and visual sensitivity must be interpreted with caution since these relationships may be due to some other common source. Yet, Weale reminds us that questions of comprehension and intelligence cannot be completely excluded.

\section{REFERENCES}

BAKER, K. Some variables influencing vernier acuity: I. Illumination and exposure time. II. Wavelength of illumination. Journal of the Optical Society of America, 1949, 39, 567-576.

BISHOP, H. P. Separation thresholds for colored bars with and without luminance contrast. Psychonomic Science, 1966a, 4, 223-224.

BISHOP, H. P. Separation thresholds for colored bars with varied luminance contrast. Psychonomic Science, 1966b, 5, 237-238.

BRODY, H. Organization of cerebral cortex. A study of aging in cerebral cortex. Journal of Comparative Neurology, 1955, 102, 511-556.

CAVONIUS, C. R., \& SCHUMACHER, A. W. Human chromatic visual acuity. Joumal of the Optical Society of America, 1965, 55, 1589.

DISPENSA, J. Differences in visual acuity. Journal of Psychology, 1939, 8, 157-163.

ECKARDT, R. A. Foveal luminosity functions of five Negroes in relation to macular and skin pigmentation. Unpublished doctoral dissertation, Fordham University, 1966.

LORANGER, A. W., \& MISIAK, H. J. Critical flicker frequency and some intellectual functions in old age. Journal of Gerontology, 1959, 14, 323-327.

MacADAM, D. Color discrimination and the influence of color contrast on visual acuity. Communication No. 1105 , Kodak Research Laboratories, 1949.

POLLACK, R. H. Contour detectability threshold as a function of age. Perceptual \& Motor Skills, 1963, 17, 411-417.

POLLACK, R. H. Hue detection thresholds as a function of chronological age. Psychonomic Science, 1965a, 3, 351-352.

POLLACK, R. H. Effects of figure-ground contrast and contour orientation on figural masking. Psychonomic Science, 1965b, 2, 369-370.

SLATON, P., \& JORGENSON, D. Visual screening in a county school for delinquent boys. American Joumal of Optometry, 1968, 35, 369-372.

WALD, G. Human vision and the spectrum. Science, 1945, 101,653-658.

WEALE, R. A. Notes on the photometric significance of the human crystalline lens. Vision Research, 1961 a, 1, 183-191.

WEALE, R. A. Retinal illumination and age. Transactions of the Illumination Engineering Society (London), 1961b, 26, 95-100.

WEALE, R. A. The aging eye. New York: Harper \& Row, 1963. Pp. 104-106, 144-148.

WILSON, K. V. A distribution-free test of analy sis of variance hypotheses. Psychological Bulletin, 1956,53, 96-101.

\section{NOTES}

1. Supported by Grant No.HD 01433 awareded by the National Institu te of Child Health and Human Development.

2. Address: Institute for Juvenile Research, 232 East Ohio Street, Chicago, Illinois 60611 .

3. Experiment 1 is based on a doctoral dissertation submitted to Loyola University, Chicago, Illinois, in partial fulfillment of the requirements for the degree of Doctor of Philosophy, June 1967.

4. The authors wish to acknowledge the invaluable suggestions and editorial assistance of their colleague, Dr. Helen W. Streicher.

5. The authors are grateful for the cooperation of Mr. Darrell Holsteen, Superintendent, School District 89, Dr. Dean W. Stoakes, Superintendent, School District 87, and principals Mr. Ronald Howard, Mr. Robert Whitaker, and Mr. John Sheahan, and their staffs.

6. Gaertner Scientific Corporation, Chicago, Illinois.

7. E. Teft and M. Wiener, Clark University, Worcester, Mass. (personal correspondence $\rightarrow$ research not published).

(Accepted for publication March 13, 1969.) 